\title{
NOTICE
}

PORTIONS OF THIS REPORT A $\cdots$ : : : : : I I

has been reproducer from the i..... . . .

copy to permit the broadest possible aya- $\quad$ UCRL 90296

atility.

PREPRINT

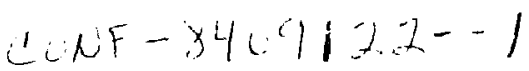

TRENDS IN OZONE AND TEMPERATURE STRUCTURE:

COMPARISON OF THEORY AND MEASUREMENTS

Donald J. Wuebbles

This paper was prepared for publication in the Proceedings of the Quadrennial ozone symposium, Halkidiki, Greece, September 3-7, 1984.

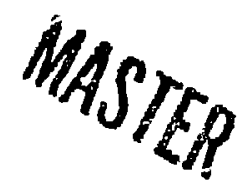

August 1984

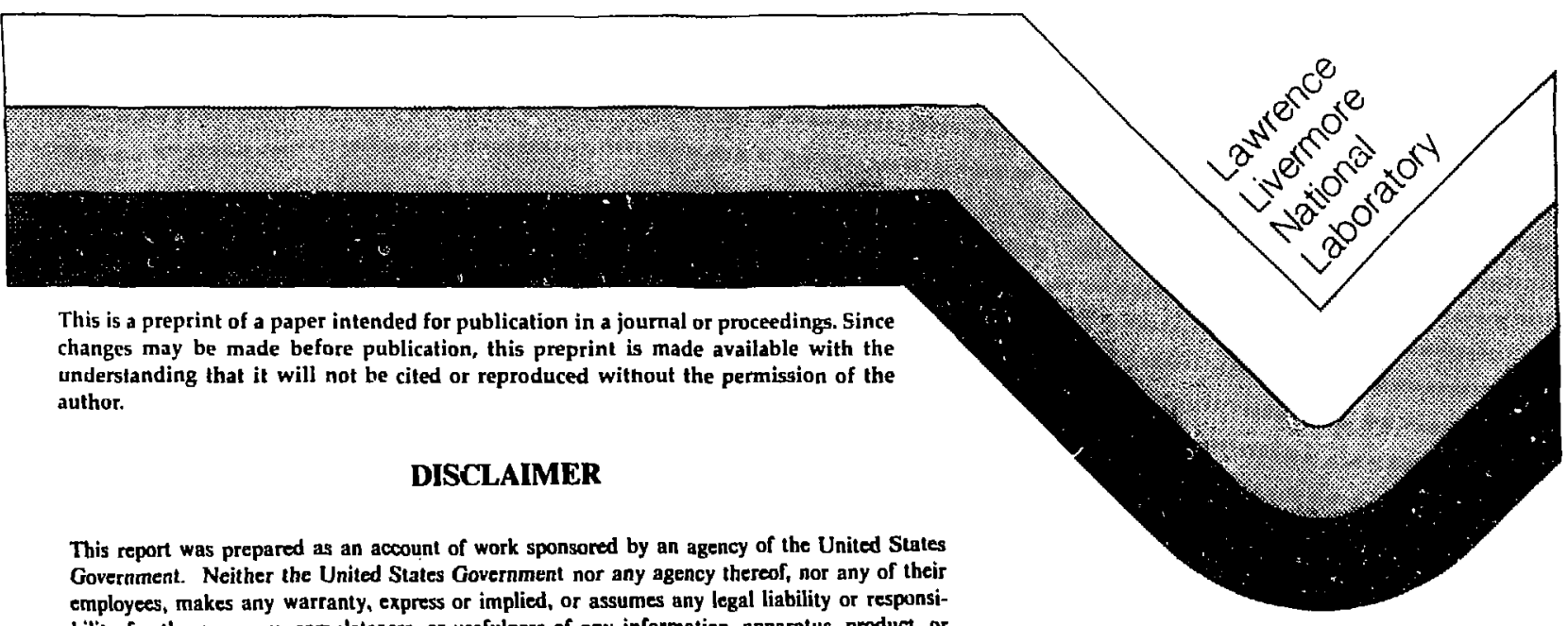

bility for the accuracy, completeness, or usefulness of any information, apparatus, product, or process disclosed, or represents that its use would not infringe privately owned rights. Reference herein to any specific commercial product, process, or service by trade name, trademark, manufacturer, or otherwise does not necessarily constitute or imply its endorsement, recommendation, or favoring by the United Stales Government or any agency thereof. The views and opinions of authors expressed herein do not necessarily state or reflect those of the United States Government or any agency thereof. 
TRENDS IN OZONE AND TEMPERATURE STRUCTURE: COMPARISUN OF THEORY AND MEASUREMENTS

\author{
Donald J. Wuebbles \\ Lawsence Livermore National Laboratory, University of California \\ Livermore, California 94550
}

\begin{abstract}
Summary
Comparison of model calculated trends in ozone and temperature due to inferred variations in trace gas concentrations and solar flux, are made with available analyses of observations. In general, the calculated trends in total ozone and the vertical ozone distribution agree well with the measured trends. However, there are too many remaining theoretical and sampling uncertainties to establish causality. Although qualitatively in agreement, the observed temperature decrease in the upper stratosphere is significantly larger than that calculated. Theoretical results suggest a significant influence on stratospheric ozone from solar flux variations, but observational evidence is at best inconclusive. Overall, the trend comparisons tend to be consistent with the hypothesis that several different anthropogenic influences are affecting the present global atmosphere.
\end{abstract}

1. Introduction

The detectability of changes in ozone and temperature, and the underlying causes of observed changes, are of particular interest because of potential anthropojenic influences. In this study, trends in ozone and temperature calculated in the LLNL one-dimensional model of the troposphere and stratosphere are compared with available analyses of observed trends. The purpose is to examine whether substantial discrepancies exist beiween current theoretical results and observed trends. Because of the limited availability of data, primary emphasis is on the comparison of measurements with model-calculated trends in ozone and temperatures during the decades of the 1960s and 1970s, and the beginning of the 1980s.

Theoretical calculations suggest that changing concentrations of a number of anthropogenically influenced trace gases may presently be alter ing the global atmospheric ozone distribution and temperature structure. Concentrations and/or emissions of gases such as $\mathrm{CO}_{2}, \mathrm{CH}_{4}, \mathrm{~N}_{2} \mathrm{O}$, several chlorocarbons (CRCs), and NO from aircraft and nuclear tests ${ }^{2}$ are varied historically based on consideration of recent emissions evaluations and atmospheric measured trends (1). A variety of natural processes and phenomena are also known to affect the stratosphere. Variations in the solar ultraviolet flux over the 11-year sunspot cycle are included in this study (case a) based on the solar emissions model of Lean et al. (2). Because of uncertainties, a second case considered only half the solar flux variation at ravelengths greater than $180 \mathrm{~nm}$ (case b). 


\section{Trends in Total Ozone}

Table 1 shows calculated changes in total ozone over recent decades for several of the scenarios examined. Cases I and II suggest that total ozone should have increased at a slow but steady rate throughout the $1960 \mathrm{~s}$ and 1970s due to the influence of trace gas emissions. This increase in ozone is primarily due to increasing concentrations of $\mathrm{CO}_{2}$ and $\mathrm{CH}_{4}$, with a significant influence frow aircraft emissions when included. A small decrease is derived in the total ozone trend when only chlorocarbons are considered.

TABLE 1. Calculated trends in total ozone (\%/time period) for periods 1960-1970, 1970-1980, and 1980-1983.

\begin{tabular}{rlccc}
\hline Case & $1960-70$ & $1970-80$ & $1980-83$ \\
\hline I $\left(\mathrm{ClC}+\mathrm{CO}_{2}+\mathrm{N}_{2} \mathrm{O}+\mathrm{CH}_{4}\right)$ & +0.30 & +0.30 & +0.09 \\
II $(\mathrm{I}+\mathrm{NO})^{2}$ & +0.42 & +0.60 & +0.20 \\
VI $\mathrm{ClC}$ only & -0.03 & -0.12 & -0.07 \\
VIII I + solar variability (a) & +1.29 & +0.71 & -2.69 \\
IX I + solar variability (b) & +0.74 & +0.49 & -1.19 \\
\hline
\end{tabular}

In evaluating the trend in total ozone during the 1960 s, it is necessary to consider the NO produced by nuclear tests of the late 1950s and early 1960s. Several data analyses suggest that a decrease in total ozone may have occurred at the time of the nuclear test series. Figure 1 shows that the calculated effect of the nuclear tests is a maximum total ozone decrease of $2.5 \%$. These results are consistent with the upper limits (< 4\%) estimated by the analyses of total ozone data. However, as seen from Fig. 1, a minimum in total ozone is also calculated for the early 1960s when considering the influence of solar cycle variations.

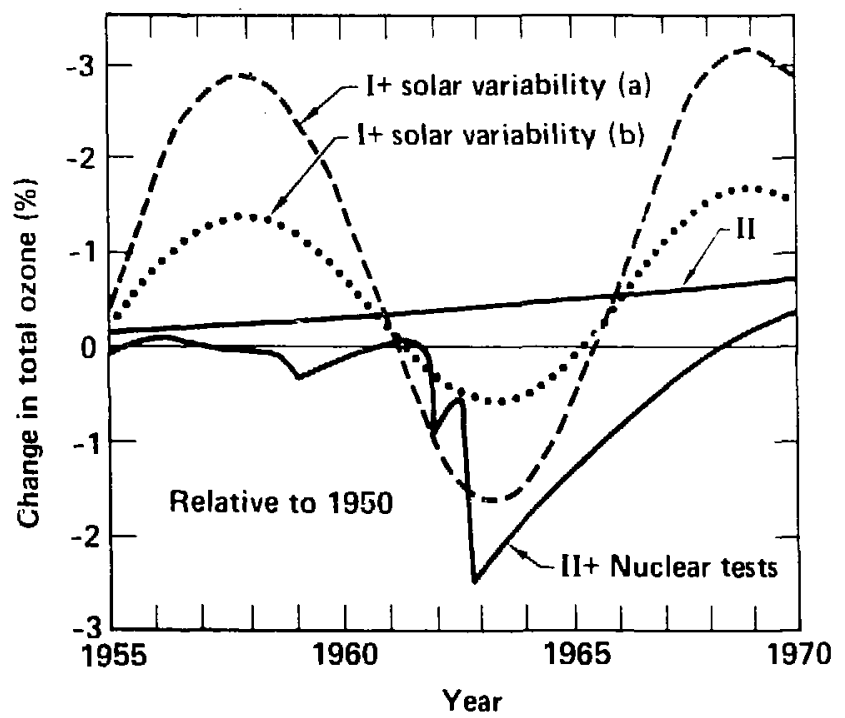

Figure 1. Calculated change in total ozone for the 1960s. 
The cases which consider the possible effects of solar cycle variations calculate a change in total ozone of approximately $2.1 \%$ (case b) to 4.4\% (case a) from solar minimum to solar maximum. Solar cycle variations could make detection of trends in total ozone due to anthropogenic influences more difficult. Observational evidence of a relationship between total ozone and solar activity is at best inconclusive. Larger than normal total ozone amounts were observed in the years of the solar maximums (3). However, a minimum in total ozone calculated to occur in 1975 is not obviously evident in the observations.

Assuming Cases I and II correspond approximately to the conditions for the Southern and Northern Hemispheres, respectively, then the results shown in Table 2 suggest a global trend of $+0.45 \%$ from $1970-1980$ due to the ef fects of trace gases. Reinsel (4), using time series statistical analysis derived the global ozone change from 1970-1980 based on Dobson total ozone column measurements to be $0.49( \pm 1.35) \%$. The measured trends from this and other similar analyses are in excellent agreement with the calculated global change when all anthropogenic emissions are considered. Unfortunately, no definitive analysis is available of the measured difierence in the trends of total ozone between hemispheres.

TABLE 2. Summary of comparison between calculated and observed trends during the 1970 s.

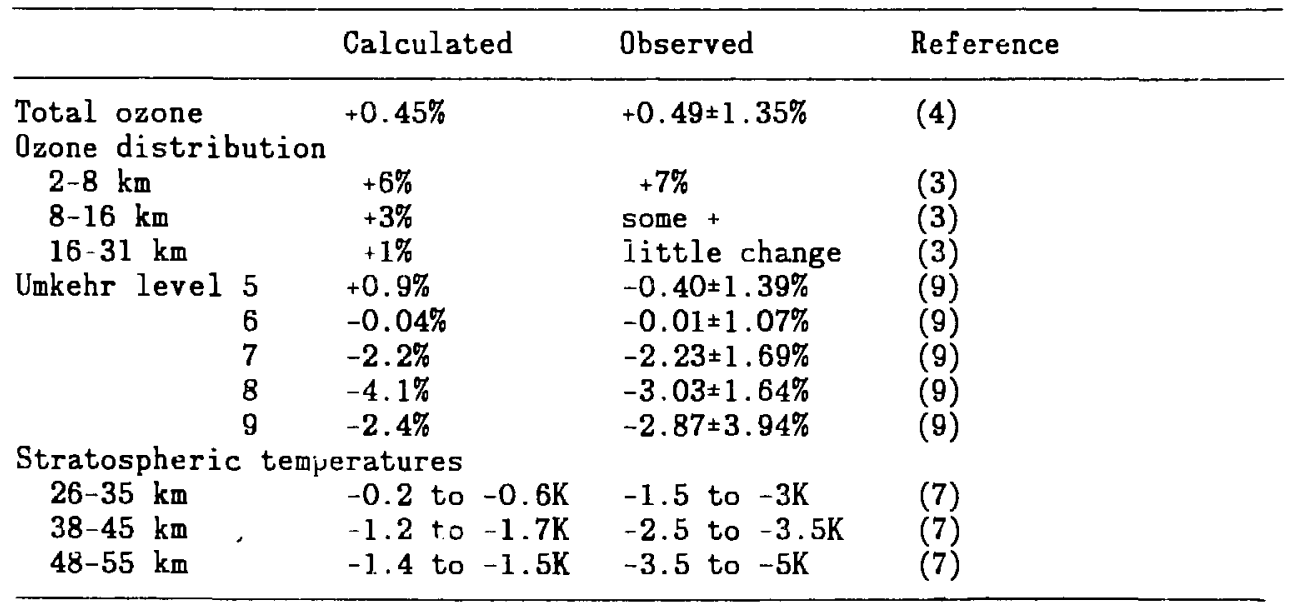

3. Trends in the Ozone Vertical Distribution

The change in ozone with pressure level is shown in Fig. 2 for Case II at selected times relative to 1950. Tropospheric and stratospheric ozone are calculated to have changed significantly during the 1970 s and $1980 \mathrm{~s}$ (to 1983). The growing calculated decrease in upper stratospheric ozone results primarily from chlorocarbon emissions. The increase in the middle stratosphere results from increasing $\mathrm{CO}_{2}$ and $\mathrm{CH}$ concentrations as well as the ozone recovery mechanism. The increase in the troposphere and lower stratosphere results from the assumed aircraft $\mathrm{NO}$ emissions and increasing CH concentrations. A maximum decrease over the $1970 \mathrm{~s}$ of $4.4 \%$ is calculated in the upper stratosphere (at $3.5 \mathrm{mb}$ ). A maximum ozone increase of $6.7 \%$ is calculated in Case II in the upper troposphere. A much smaller increase ( $-2 \%$ at the surface and $41 \%$ in upper troposphere) is determined for the Southern Bemisphere (Case I) troposphere, which does not include aircraft emissions. 


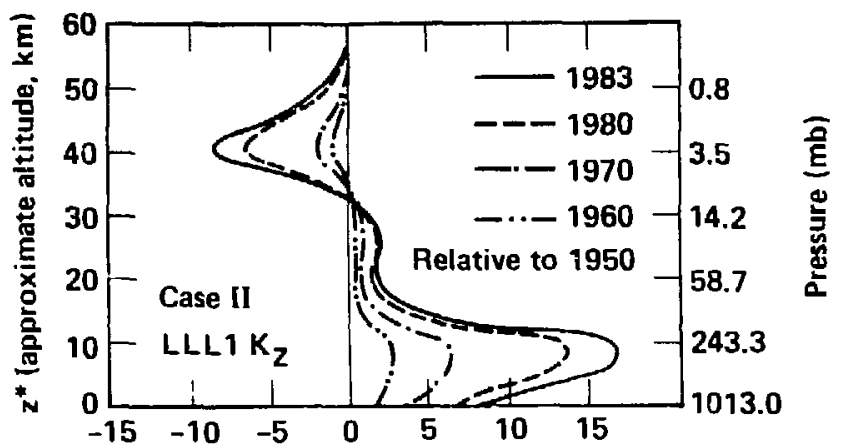

Change in local ozone (\%)

Figure 2. Calculated percentage change in ozone for Case II at selected times relative to 1950 .

By comparison, ozonesonde measurements in the tropospheric layer from $2-8 \mathrm{~km}$ in northern temperate latitudes suggest nearly a $7 \%$ ozone increase during the last decade $(3,5 ;$. Little change was found in Southern Hemisphere data. The limited amount of data makes interpretation of these analyses highly uncertain. Some ozone increase in Northern Hemisphere data is also indicated for the 8-16 km layer with little change in ozone from 16 to $32 \mathrm{~km}$ (3). Umkehr data for upper stratospheric ozone have recently been reanalyzed to correct for potential errors, such as those due to atmospheric aerosols and changes in instrumentation (6). Calculated trends are within the observation confidence limits at all levels (see Table 2).

\section{Trends in Upper Air Temperatures}

Figure 3 shows the calculated change in stratospheric lemperatures at selected times from January 1950 to January 1983. The stratosphere is calculated to cool throughout this period, primarily due to the increasing $\mathrm{CO}$ concentrations, but also due to decreasing ozone amounts in the upper stratosphere. The largest cooling occurs at approximately $2.4 \mathrm{mb}(-42.5$ $\mathrm{km}$ ). Radiosonde data (7) at 16-24 $\mathrm{km}$ suggest a small decrease in temperature of approximately 0.2-0.4 K during the 1960s, in good general agreement with the calculated results. Measured trends at higher altitudes during the 1960 s were not available for comparison. From January 1970 to January 1980 , the maximum calculated temperature change of $-1.7 \mathrm{~K}$ occurred in both Cases I and II at $2.4 \mathrm{mb}$. Similar upper air temperature changes are calculated for both the Northern and Southern Hemispheres. The calculations agree qualitatively with the analysis of rocketsonde data (7) of a surface and tropospheric warming and stratuspheric cooling during the past decade. Bowever, the data suggest larger changes in stratospheric temperatures during the 1970s than are calculated (see Table 2). Such a large change in temperature, if real and not due to sampling errors, requires additional theoretical analysis as to its cause. It is difficult to develop a mechanism for explaining the large observed decrease in temperature. A larger cooling than that calculated would add to the calculated increase in total ozone over the decade and reduce the magnitude of the calculated decreases in upper stratosphere ozone.

\section{Discussion}

Table 2 summarizes the comparisons trends in ozone and temperature for the of calculated and observed global lated trends in 


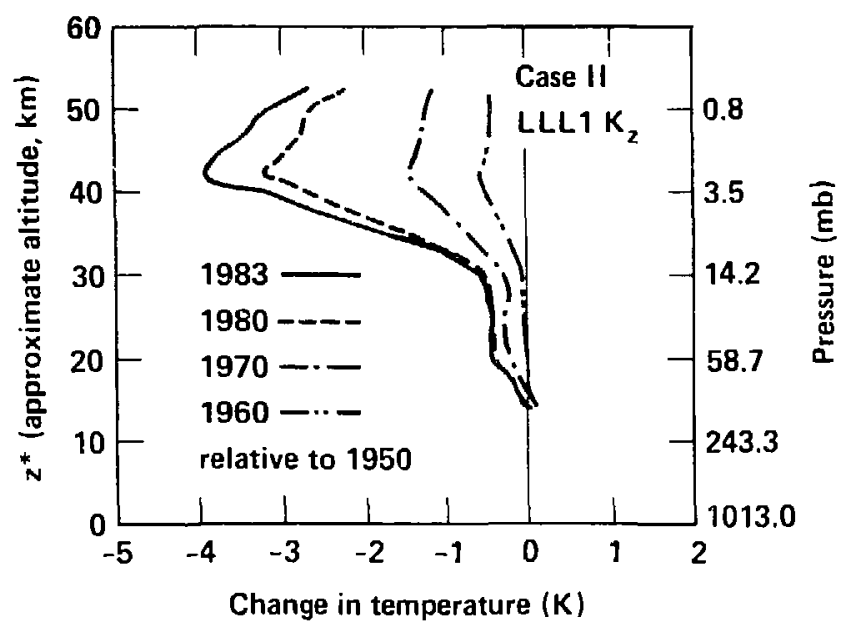

Figure 3. Calculated changes in stratospheric temperatures for Case II at selected times relative to January 1950.

in agreement with the measured trends, there are too mąny remaining theoretical and sampling uncertainties for causality to be established. Overall, the trend comparisons tend to be consistent with the hypothesis that several different anthropogenic influences are affecting the present global atmosphere.

This work was performed under the auspices of the U.S. Department of Energy by the Lawrence Livermore National Laboratory under Contract W-7405Eng-48 and supported in part by the Environmental Protection Agency.

\section{REFERENCES}

1. WUEBBLES, D. J., M. C. MACCRACKEN, and F. M. LUTHER (1984). A proposed reference set of scenarios for raditively active atmospheric constituents. U. S. Department of Energy Carbon Dioxide Research Division Technical Report, in press.

2. LEAN, J. L., O. R. WHITE, W. C. LIVINGSTON, D. F. HEATH, R. F. DONNELLY and A. SKUMANICH (1982). A three component model of the variability of the solar ultraviolet flux: 145-200 nm. J. of Geophys.Res., 87 , $10307-10317$.

3. ANGELL, J. K., and J. KORSHOVER (1983a). Global Variation in total ozone and layer-mean ozone: an update through 1981. J.of Climate and Appl.Met. , 22, 1611-1627.

4. REINSEL, G. C. (1981). Analysis of total ozone data for the detection of recent trends and the effects of nuclear testing during the 1960's. Geophys. Res. Lett., 8, 1227-1230.

5. WORLD METEOROLOGICAL ORGANIZATION (1981). The stratosphere 1981: theory and measurements. WMO global ozone research and monitoring project report No. 11 .

6. REINSEL, G. C. , TIA0, G. C., DELUISI, J. J., MATEER, \%. L., iILLER, A. J., and FREDERICK, J. E. (1984). Analysis of upper stratospheric Umkehr ozone profile data for trends and the effect of stratospheric aerosols. J. Geophys. Res., 89, 4833-4840.

7. ANGELL, J. K. and KORSHOVER, J. (1983b). Global temperature variations in the tropospheri and stratosphere, 1958-1982. Monthly Weather Review, 111, 901-921. 